\title{
Research Trends in Off-Site Construction Management: Review of Literature at the Process Level
}

\author{
Jun Young Jang ${ }^{1}$, Chansik Lee ${ }^{2}$, Jung In $\mathrm{Kim}^{3}$, and Tae Wan $\mathrm{Kim}^{4 *}$ \\ ${ }^{1}$ Ph.D. candidate, Dept. of Architecture, Incheon National University \\ ${ }^{2}$ Professor, Dept. of Architecture, Incheon National University \\ ${ }^{3}$ Assistant Professor, Dept. of Architecture and Civil Engineering, City University of Hong Kong \\ ${ }^{4}$ Assistant Professor, Dept. of Architecture, Incheon National University \\ "Corresponding author's e-mail: taewkim@inu.ac.kr
}

\begin{abstract}
Off-Site Construction (OSC) is a new construction method based on factory production. Due to its advantages over traditional methods, such as high productivity, economic efficiency, and excellence in quality, OSC research has actively been conducted worldwide ranging from design and production standardization, transportation method, to construction planning. Thus, to understand what knowledge has been developed to improve the management of OSC projects, this study reviewed OSC papers that focus on improving a specific project management area (e.g., time, cost, and quality) in a specific phase of a project, i.e., "process-level research." This study found 94 papers with such a focus, out of 222 OSC project management papers published from 1986 to 2018, and assessed the trends of the research with multiple dimensions, including project phases, OSC types, application types, and management areas. Main findings are as follows: (1) process-level research has been increasing fast since 2006. (2) Non-volumetric pre-assembly type contributes the most to the increase of process-level OSC management research. (3) Research focuses vary depending on the application type (e.g., living quality issues for residential, economics issues for non-residential, productivity issues for plant). (4) Wider project management areas (e.g., quality, human resources, risk) have gained attention from OSC papers since 2006. (5) Non-volumetric type gained interests in residential and non-residential buildings, whereas modular type was studied frequently in plants. This study would help project management researchers understand the trends in OSC and plan and conduct future OSC project management research.
\end{abstract}

\section{KEYWORDS}

Literature review; Off-site construction; Project management; Modular method.

\section{INTRODUCTION}

The construction industry is highly affected by external factors such as social and environmental factors. Therefore, without changing such factors including aging, lack of manpower, and weather factors, the construction industry will not be able to overcome project delays and costoverruns dramatically. To solve these problems, there is an increasing interest in off-site construction (OSC) methods in many countries including the UK and the USA because OSC has high potential to alleviate the impacts of such factors and improve in productivity, economy, and 
product quality. To improve research on OSC, some literature review studies were carried out. For example, Li et al. (2014) collected 100 prefabrication project management papers and performed a qualitative analysis to identify five predominant research topics. O'Neill and Organ (2016) summarized the history of the use of prefabs in the UK low-rise building from the 12th century to the present. Kamali and Hewage (2016) reviewed literature on the benefits and challenges of modular construction and on the lifecycle assessment of modular construction. Jin et al. (2018) and Hosseini et al. (2018) conducted a scientometric analysis of OSC papers to determine the quantitative relationships among the papers, including co-authorship, citations, cooccurrence of keywords, etc. Zakaria et al. (2018) summarized contextual, structural, and behavioral factors that influence OSC adoption through literature review. These studies provide insights to OSC researchers who would like to find valuable topics and make their own contributions. However, they do not offer extensive knowledge on what OSC research has been done in what project management area over time, which would help OSC project management researchers understand the trends and plan and conduct future project management research. Therefore, this study aims to review OSC papers that focus on improving a specific project management area (e.g., time, cost, quality) in a specific phase of a project - this paper calls them "process-level research" papers as opposed to industry- or project-level research papers.

\section{METHODS}

The authors first determined the following four dimensions to classify the papers and grasp the trends in OSC project management research:

- Project phases: planning, design, manufacturing, transportation, assembly, maintenance

- OSC types: component manufacture and subassembly, non-volumetric pre-assembly, volumetric pre-assembly, modular building (Gibb and Isack 2003)

- Applications: residential, non-residential, and industrial facilities

- Management areas: integration management, time management, cost management, quality management, human resources management, risk management, procurement management, stakeholder management (PMI 2013)

Then, the authors searched for related papers utilizing Web of Science (WoS) and Scopus search tools, which are commonly used in other OSC literature review papers (Hosseini et al. 2018; Jin et al. 2018), on Sep. 3, 2018. In consideration of the keywords used in other papers and the aforementioned dimensions, this study used the following keywords: TITLE-KEY: ("off-site construction" OR "offsite construction" OR "prefabricated construction" OR "industrialized construction" OR "modular construction" OR "precast construction" OR "modern methods of construction" OR "modular construction and project” OR "prefabrication construction").

The keyword search originally found 1,042 papers written in English. The authors then excluded 155 unrelated papers by assessing their keywords and titles and 169 unrelated papers by assessing their abstracts (e.g., modularization in computer chip design). In addition, 496 papers that contribute other fields than project management, such as structural, design, and building systems, were excluded to leave 222 project management papers in OSC. These papers consist of 48 industry-level research papers (e.g., success factors of industry building system (Rashidi and Ibrahim 2017)), 80 project-level research papers (e.g., comparison between precast and existing systems (Chen et al. 2010)), and 94 process-level research papers. As for the scope, this study analyzed these 94 process-level papers in different dimensions over time. This study also 
conducted the cross-tabular analysis between OSC types and applications and between phases and management areas.

\section{FINDINGS}

\section{Trends of OSC management papers over time}

The trends of OSC project management papers published from 1986 to 2018 were identified (Figure 1). The number of OSC project management papers in industry, project, and process level has increased significantly since 2006. Specifically, the number of papers published in recent three years (2016-18) is the same as the number of papers published between 1986 and 2015.

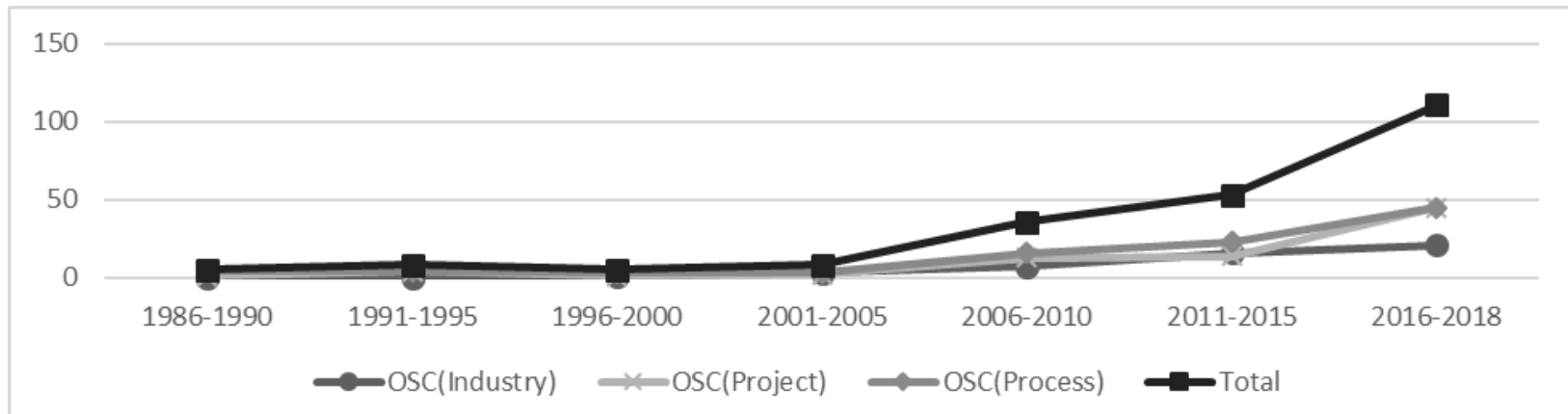

Figure 1. OSC project management papers trends 1986-2018 (Total: 222)

\section{Trends of process-level OSC management papers over time}

Project phases of the papers

Figure 2 shows that (1) OSC research that intends to contribute to the manufacturing and assembly phases has continuously been carried out and (2) research has been expanded to other OSC project phases, including planning, design, transportation, and maintenance (e.g., stakeholder participation management (Xue et al. 2018) and supply chain information management (Niu et al. 2017)).

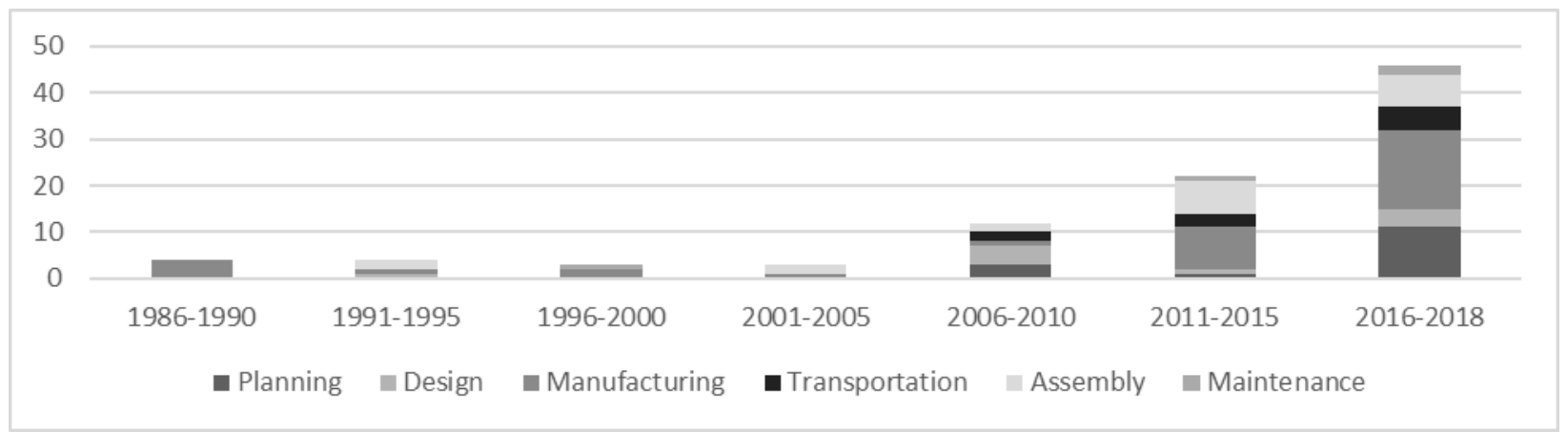

Figure 2. Trends of process-level OSC management papers by phases (Total:94)

OSC types of the papers

During the period from 1986 to 2018, studies on the non-volumetric pre-assembly type have increased significantly, followed by the modular and the component manufacture types (Figure 3 ). The components that are frequently seen in the non-volumetric pre-assembly type are precast 
concrete, steel, and wood. Research on such type includes detailed design of prefabricated building (Retik and Warszawskit 1994), production scheduling and tool development (Benjaoran and Dawood 2006; Leu and Hwang 2002), decision-making on components and assembly methods (Pereyra and Romero 2009; Chen et al. 2010), transportation and on-site assembly (Wang et al. 2018), in the order of time. Studies on modular building project management include the development of tools and applications for productivity improvement (Han et al. 2012; Moghadam et al. 2012) and the quality control of the modular products (Kim et al. 2016; Yu et al. 2013). Studies on the component manufacture and subassembly type include the assembly method through on-site production (Altobelli et al. 1993; Herkommer and Bley 1996), manufacture schedule (Wang and $\mathrm{Hu} 2018$ ), and production planning considering the worker safety (Kim et al. 2008).

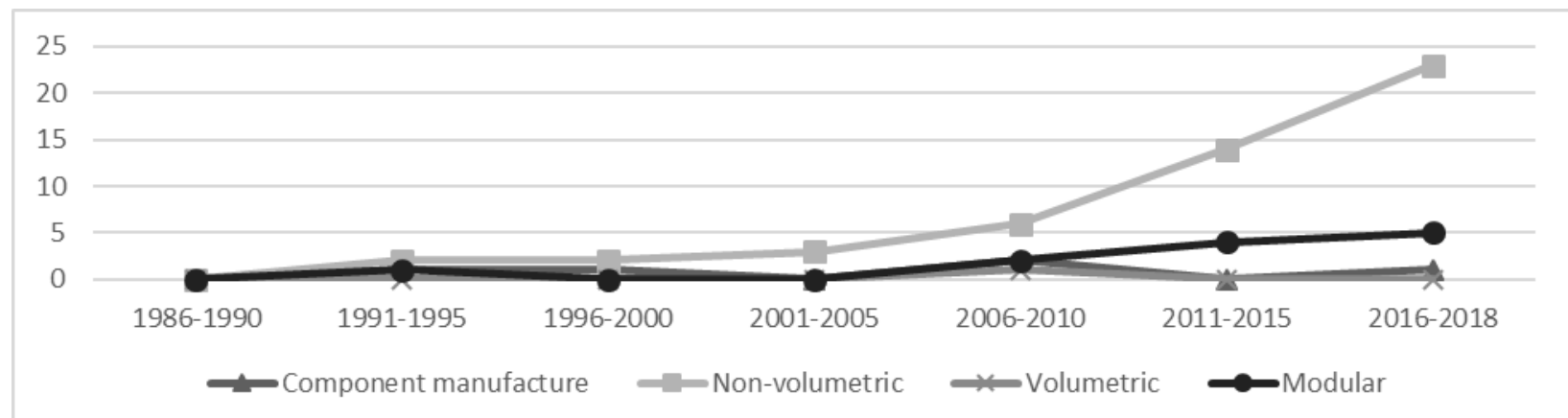

Figure 3. Trends of process-level OSC management papers by OSC types (total: 68; missing: 26)

Applications of the papers

Residential research accounts for the largest parts of the papers (56\%), followed by nonresidential and plants. In the case of residential buildings, studies on the convenience of the residents, such as the design plan (Jaillon and Poon 2010), quality of buildings (Jonsson and Rudberg 2017), and building maintenance (Švajlenka and Kozlovská 2018), were mainly carried out. As for the non-residential buildings, many papers deal with the economic feasibility of the projects for the owners, such as construction scheduling (Moghadam et al. 2012; Salama et al. 2017) and decision making considering stakeholders (Finnie et al. 2018). Lastly, studies related to plants seem to focus on productivity improvement, such as transportation management of OSC components (Tam et al. 2007) and material procurement process integration plan (Jo et al. 2018).

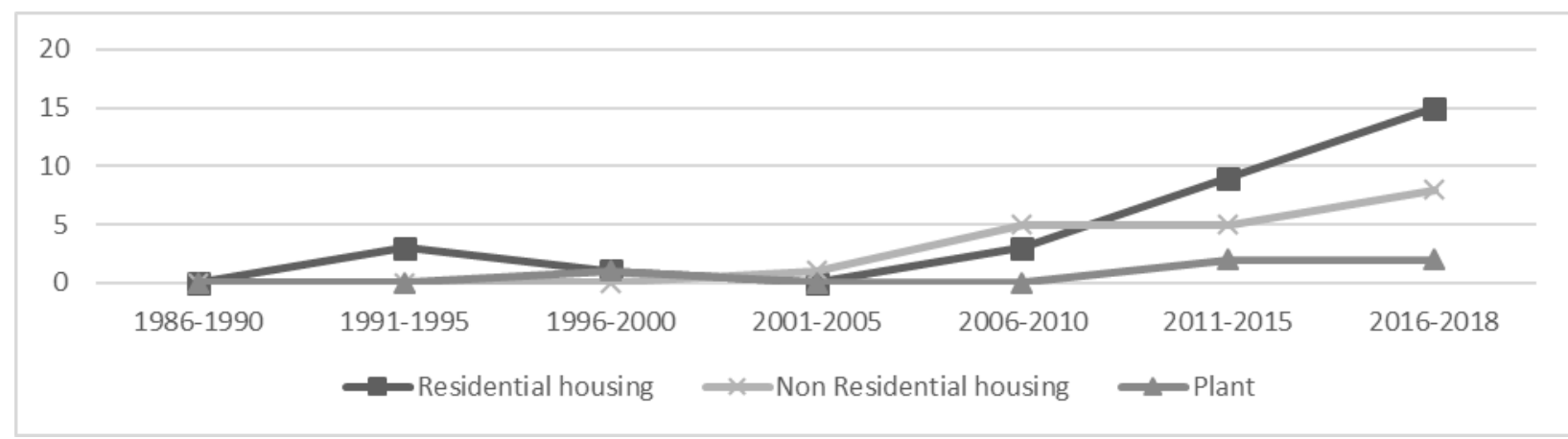

Figure 4. Trends of process-level OSC management papers by applications (Total: 55; missing: 39) 


\section{Management area of the papers}

Table 1 shows the number of the papers over time by management areas. Procurement $(22 \%)$, time $(18 \%)$, and integration management $(16 \%)$ are the most frequently studied management areas. During 1986-2000, studies on integration and safety management were of interest. During 2001-2010, the research interests shifted to procurement and integration management. Since 2011, the research focus has rapidly been expanded to other management areas, such as time, cost, quality, human resources, risk, and stakeholder management.

Table 1. Number of journals in the project management area from 1986 to 2018

\begin{tabular}{lccccccccccc}
\hline & $\begin{array}{c}\text { Integra- } \\
\text { tion }\end{array}$ & Time & Cost & Quality & $\begin{array}{c}\text { Human } \\
\text { Resources }\end{array}$ & $\begin{array}{c}\text { Procure- } \\
\text { ment }\end{array}$ & Risk & $\begin{array}{c}\text { Stake- } \\
\text { holder }\end{array}$ & Safety & $\begin{array}{c}\text { Maint- } \\
\text { enance }\end{array}$ & Total \\
\hline $1986-1990$ & 0 & 0 & 0 & 0 & 0 & 0 & 0 & 0 & 4 & 0 & 4 \\
$1991-1995$ & 2 & 1 & 0 & 0 & 0 & 0 & 0 & 1 & 0 & 0 & 4 \\
$1996-2000$ & 1 & 0 & 0 & 0 & 0 & 1 & 0 & 0 & 0 & 1 & 3 \\
$2001-2005$ & 1 & 2 & 0 & 0 & 0 & 0 & 0 & 0 & 0 & 0 & 3 \\
$2006-2010$ & 5 & 0 & 1 & 0 & 0 & 4 & 0 & 1 & 1 & 0 & 12 \\
$2011-2015$ & 3 & 5 & 2 & 2 & 3 & 5 & 2 & 0 & 2 & 0 & 24 \\
$2016-2018$ & 3 & 9 & 3 & 6 & 2 & 11 & 3 & 4 & 1 & 2 & 44 \\
Total & 15 & 17 & 6 & 8 & 5 & 21 & 5 & 6 & 8 & 3 & 94 \\
\hline
\end{tabular}

\section{Multi-dimensional analysis}

Cross-tabulations of OSC types and applications

Table 2 shows the results of cross-tabulations analysis of the OSC types and applications. Residential housing studies consist of $69 \%$ of the non-volumetric type papers and $19 \%$ of the modular type papers. Similarly, most of the non-residential housing studies also dealt with nonvolumetric pre-assembly as their OSC types. This finding reinforces Jin et al.' study (2018) which states that studies on precast concrete (non-volumetric type) has recently been increasing in the OSC research domain.

Table 2. Cross-tabulation of process-level OSC management papers by OSC types and applications (Total: 43; Unknown:51)

\begin{tabular}{lcccc}
\hline \multicolumn{1}{c}{ OSC types } & Residential housing & Non-Residential housing & Plant & Total \\
\hline Component manufacture & 2 & 1 & 1 & 3 \\
Non-volumetric & 18 & 11 & 0 & 30 \\
Volumetric & 1 & 0 & 2 & 1 \\
Modular & 5 & 2 & 3 & 9 \\
Total & 26 & 14 & 43 \\
\hline
\end{tabular}

\section{Cross-Tabulation of project phases and management areas}

The process-level OSC management papers were classified into 6 phase and 10 management areas in the cross-tabular analysis (Table 3). It was found that the research has frequently been conducted on the manufacturing (38\%; mainly in the procurement, time, and quality management areas), assembly (21\%; mainly in the time and integration management areas), and planning phases (15\%; mainly in the integration and cost management areas). Many procurement management studies were conducted for the manufacturing phase of OSC projects because they are related to reliable factory production and supply chain management that support just-in-time supply of OSC components to on-site (Zhai et al. 2017). Time management studies are frequent in both the manufacturing and the assembly phases as developing component production 
schedules off-site (Arashpour et al. 2016) and developing assembly plans and schedules on-site (Li et al. 2018) are both critical to the success of OSC projects.

Table 3. Cross-tabulation of process-level OSC management papers by project phases and management areas

\begin{tabular}{|c|c|c|c|c|c|c|c|}
\hline & Plan & Design & Manufacture & Transportation & Assembly & Maintenance & Total \\
\hline Integration management & 3 & 3 & 1 & 0 & 7 & 1 & 15 \\
\hline Time Management & 1 & 1 & 6 & 1 & 8 & 0 & 17 \\
\hline Cost Management & 3 & 0 & 1 & 0 & 2 & 0 & 6 \\
\hline Quality Management & 0 & 2 & 6 & 0 & 0 & 0 & 8 \\
\hline Human Resources Management & 0 & 1 & 3 & 1 & 0 & 0 & 5 \\
\hline Procurement management & 0 & 1 & 12 & 7 & 0 & 0 & 20 \\
\hline Risk management & 2 & 0 & 0 & 1 & 1 & 0 & 4 \\
\hline Stakeholder Management & 5 & 0 & 3 & 0 & 0 & 0 & 8 \\
\hline Safety management & 0 & 2 & 4 & 0 & 2 & 0 & 8 \\
\hline Maintenance Management & 0 & 0 & 0 & 0 & 0 & 3 & 3 \\
\hline Total & 14 & 10 & 36 & 10 & 20 & 4 & 94 \\
\hline
\end{tabular}

\section{CONCLUSION}

OSC research has actively been conducted worldwide ranging from design and production standardization, transportation method, to construction planning. Therefore, to understand what knowledge has been developed to improve the management of OSC projects, this study reviewed OSC papers that focus on improving a specific project management area (e.g., time, cost, and quality) in a specific phase of a project, i.e., "process-level research." Specifically, this study reviewed 94 papers with such a focus, published from 1986 to 2018, to derive the trends of the process-level OSC management research with multiple dimensions, i.e., project phases, OSC types, application types, and management areas.

Main findings are as follows: (1) the number of OSC project management papers in industry, project, and process level has increased significantly since 2006. (2) OSC research that intends to contribute to the manufacturing and assembly phases has continuously been carried out, and it has been expanded to other OSC project phases, including planning, design, transportation, and maintenance. (3) Studies on the non-volumetric pre-assembly type have increased significantly, followed by the modular and the component manufacture types. (4) Research focuses vary depending on the application type (i.e., living quality issues for residential, economics issues for non-residential, productivity issues for plant). (5) Procurement, time, and integration management are the most frequently studied management areas. (6) Non-volumetric type gained interests in residential and non-residential buildings, whereas modular type was studied frequently in plants. (7) Research has frequently been conducted on the manufacturing (mainly in the procurement, time, and quality management areas), assembly (mainly in the time and integration management areas), and planning phases (mainly in the integration and cost management areas).

This study would help project management researchers understand the trends in OSC and plan and conduct future OSC project management research. To gain the full potential of this study, further research should be conducted including the review of the industry- and projectlevel studies, assessment of the studies with more dimensions, such as dealt problems and the data used in the studies, and assessment of new technologies involved in the studies, such as building information modeling (BIM) and sensors. 
MOC SUMMIT / MAY 2019

\section{REFERENCES}

Altobelli, F., Taylo, H., and Bernold, L. (1993). "The International Institute of Production Engineering Research ( CIRP ).” Journal of Aerospace Engineering, 6(1), 19-33.

Arashpour, M., Wakefield, R., Abbasi, B., Lee, E., and Minas, J. (2016). "Off-site construction optimization: Sequencing multiple job classes with time constraints.” Automation in Construction, 71, 262-270.

Benjaoran, V., and Dawood, N. (2006). "Intelligence approach to production planning system for bespoke precast concrete products." Automation in Construction, 15(6), 737-745.

Chen, Y., Okudan, G., and Riley, D. (2010). "Decision support for construction method selection in concrete buildings: Prefabrication adoption and optimization." Automation in Construction, 19(6), 665-675.

Finnie, D., Ali, N., and Park, K. (2018). "Enhancing off-site manufacturing through early contractor involvement (ECI) in New Zealand." Management Procurement and Law, 171(4), 176-185.

Gibb, A., and Isack, F. (2003). "Re-engineering through pre-assembly: Client expectations and drivers." Building Research and Information, 31(2), 146-160.

Han, S., Al-Hussein, M., Al-Jibouri, S., and Yu, H. (2012). "Automated post-simulation visualization of modular building production assembly line." Automation in Construction, 21, 229-236.

Herkommer, F., and Bley, B. (1996). "CAD/CAM for the prefabrication of brickwork." Automation in Construction, 4(4), 321-329.

Hosseini, M., Martek, I., Zavadskas, E., Aibinu, A., Arashpour, M., and Chileshe, N. (2018). "Critical evaluation of off-site construction research: A Scientometric analysis." Automation in Construction, 87, 235-247.

Jaillon, L., and Poon, C. (2010). "Design issues of using prefabrication in hong kong building construction." Construction Management and Economics, 28(10), 1025-1042.

Jin, R., Gao, S., Cheshmehzangi, A., and Aboagye-Nimo, E. (2018). "A Holistic Review of offsite Construction Literature Published between 2008 and 2018." Journal of Cleaner Production, 202, 1202-1219.

Jo, S., Lee, E., and Pyo, K. (2018). "Integrating a Procurement Management Process into Critical Chain Project Management (CCPM): A Case-Study on Oil and Gas Projects, the Piping Process." Sustainability, 10(6), 1817.

Jonsson, H., and Rudberg, M. (2017). "KPIs for measuring performance of production systems for residential building: A production strategy perspective." Construction Innovation, 17(3), 381-403.

Kamali, M., and Hewage, K. (2016). "Life cycle performance of modular buildings: A critical review." Renewable and Sustainable Energy Reviews, 62, 1171-1183.

Kim, S., Seol, H., Ikuma, L., and Nussbaum, M. (2008). "Knowledge and opinions of designers of industrialized wall panels regarding incorporating ergonomics in design." International Journal of Industrial Ergonomics, 38(2), 150-157.

Leu, S., and Hwang, S. (2002). "GA-based resource-constrained flow-shop scheduling model for mixed precast production." Automation in Construction, 11(4), 439-452.

Li, C., Xu, X., Shen, G., Fan, C., Li, X., and Hong, J. (2018). “A model for simulating schedule risks in prefabrication housing production: A case study of six-day cycle assembly activities in Hong Kong." Journal of Cleaner Production, 185, 366-381. 
Li, Z., Shen, G., and Xue, X. (2014). "Critical review of the research on the management of prefabricated construction." Habitat International, 43, 240-249.

Moghadam, M., Al-Hussein, M., Al-Jibouri, S., and Telyas, A. (2012). "Post simulation visualization model for effective scheduling of modular building construction." Canadian Journal of Civil Engineering, 39(9), 1053-1061.

Niu, Y., Lu, W., Liu, D., Chen, K., Anumba, C., and Huang, G. (2017). “An SCO-Enabled Logistics and Supply Chain-Management System in Construction." Journal of Construction Engineering and Management, 143(3).

O'Neill, D., and Organ, S. (2016). "A literature review of the evolution of British prefabricated low-rise housing." Structural Survey, 34(2), 191-214.

PMI. (2013). A Guide to the Project Management Body of Knowledge. In (5 $5^{a}$ ed.). Pennsylvania: Project Management Institute, Inc.

Pereyra, J., and Romero, S. (2009). "Technical and economical simulation of two roofing construction systems in southeast Mexico.” Revista Ingenieria de Construccion, 24(2), $167-180$.

Rashidi, A., and Ibrahim, R. (2017). "Industrialized Construction Chronology: The Disputes and Success Factors for a Resilient Construction Industry in Malaysia." The Open Construction and Building Technology Journal, 11(1), 286-300.

Retik, A., and Warszawskit, A. (1994). "Automated Design of Prefabricated Building." Building and Environment, 29(4), 421-436.

Salama, T., Salah, A., Moselhi, O., and Al-Hussein, M. (2017). "Near optimum selection of module configuration for efficient modular construction." Automation in Construction, 83, 316-329.

Švajlenka, J., and Kozlovská, M. (2018). "Houses based on wood as an ecological and sustainable housing alternative-Case study." Sustainability, 10(5), 1502.

Tam, V., Tam, C., and Ng, W. (2007). "On prefabrication implementation for different project types and procurement methods in Hong Kong." Journal of Engineering, Design and Technology, 5(1), 68-80.

Wang, Y., Yuan, Z., and Sun, C. (2018). "Research on Assembly Sequence Planning and Optimization of Precast Concrete Buildings." Journal of Civil Engineering and Management, 24(2), 106-115.

Wang, Z., and Hu, H. (2018). "Dynamic response to demand variability for precast production rescheduling with multiple lines.” International Journal of Production Research, 56(16), 5386-5401.

Xue, H., Zhang, S., Su, Y., Wu, Z., and Yang, R. (2018). "Effect of stakeholder collaborative management on off-site construction cost performance." Journal of Cleaner Production, 184, 490-502.

Yu, H., Al-Hussein, M., Al-Jibouri, S., and Telyas, A. (2013). "Lean Transformation in a Modular Building Company: A Case for Implementation." Journal of Management in Engineering, 29(1), 103-111.

Zakaria, S., Gajendran, T., Rose, T., and Brewer, G. (2018). "Contextual, structural and behavioural factors influencing the adoption of industrialised building systems: a review." Architectural Engineering and Design Management, 14(1-2), 3-26.

Zhai, Y., Zhong, R., Li, Z., and Huang, G. (2017). "Production lead-time hedging and coordination in prefabricated construction supply chain management." International Journal of Production Research, 55(14), 3984-4002. 